\title{
N-Cadherin Redistribution during Synaptogenesis in Hippocampal Neurons
}

\author{
Deanna L. Benson ${ }^{1}$ and Hidekazu Tanaka ${ }^{2}$ \\ ${ }^{1}$ Fishberg Research Center for Neurobiology and ${ }^{2}$ Brookdale Center for Developmental and Molecular Biology, Mount \\ Sinai School of Medicine, New York, New York 10029
}

\begin{abstract}
Cadherins are homophilic adhesion molecules that, together with their intracellular binding partners the catenins, mediate adhesion and signaling at a variety of intercellular junctions. This study shows that neural $(\mathrm{N})$-cadherin and $\beta$-catenin, an intracellular binding partner for the classic cadherins, are present in axons and dendrites before synapse formation and then cluster at developing synapses between hippocampal neurons. $\mathrm{N}$-cadherin is expressed initially at all synaptic sites but rapidly becomes restricted to a subpopulation of excitatory synaptic sites. Sites of GABAergic, inhibitory synapses in mature cultures therefore lack $\mathrm{N}$-cadherin but are associated with clusters of $\beta$-catenin, implying that they contain a different
\end{abstract}

Cadherins comprise an extensive family of type I glycoproteins having large, extracellular N-terminal domains and smaller, intracellular C-terminal domains (Geiger and Ayalon, 1992). The "classic" cadherins were the first to be discovered and are named according to where they were found initially, E-cadherin from epithelial cells, N-cadherin from neural epithelium, and P-cadherin from placenta (Hatta and Takeichi, 1986; Geiger and Ayalon, 1992; Grunwald, 1996); but each of these proteins has subsequently been shown to have a much broader tissue distribution (Geiger and Ayalon, 1992). The adhesive properties of classic cadherins are undisputed. It has been stated that "as long as cadherins are functioning, other adhesion systems have little effect on cell-cell adhesion" (Takeichi, 1991). In the presence of calcium, they bind tightly and usually homophilically to one another (Nose et al., 1990; Amagai et al., 1992) through a complex set of interactions occurring in the first (EC1) of five extracellular domains (Nose et al., 1990; Overduin et al., 1995; Shapiro et al., 1995). Adhesion also requires the C-terminal cytoplasmic domain that is highly conserved among the cadherins and serves to link extracellular adhesion with actin cytoskeleton via the catenin polypeptides $(\alpha-, \beta$-, and $\gamma$-) (Nagafuchi and Takeichi, 1988, 1989; Ozawa et al., 1990; Knudsen et al., 1995; Rimm et al., 1995), two of which $(\alpha$ and $\beta$ ) have been localized to the synaptic

Received April 23, 1998; revised June 15, 1998; accepted June 23, 1998.

This research was supported by National Science Foundation Grant IBN-9419900 and National Institutes of Health Grant AG15204-01 to D.L.B. H.T. was supported by 5 P01 NS33165 from the National Institutes of Health. We thank Melba Nagy and Sophie Kay for excellent technical assistance, Drs. Karen Knudsen and David Colman for their gifts of antibodies, and Drs. George Huntley, David Colman, Javier DeFelipe, and Adam Gazzaley for valuable discussions and comments on this manuscript.

Correspondence should be addressed to Dr. Deanna L. Benson, Fishberg Research Center for Neurobiology, Box 1065, Mount Sinai School of Medicine, 1425 Madison Avenue, New York, NY 10029.

Copyright (C) 1998 Society for Neuroscience $0270-6474 / 98 / 186892-13 \$ 05.00 / 0$ classic cadherin. These findings indicate that $\mathrm{N}$-cadherin adhesion may stabilize early synapses that can then be remodeled to express a different cadherin and that cadherins systematically differentiate between functionally (excitatory and inhibitory) and spatially distinct synaptic sites on single neurons. These results suggest that differential cadherin expression may orchestrate the point-to-point specificity displayed by developing synapses.

Key words: $N$-cadherin; $\beta$-catenin; synaptogenesis; synaptic junctional complex; presynaptic membrane; postsynaptic membrane; PSD; wnt/wingless

junctional complex and are known to associate with multiple cadherin subtypes (Uchida et al., 1996). At this time, almost 40 cadherin and cadherin-related molecules have been reported in the brain, supporting their potential for adhesive specificity (Ranscht and Dours-Zimmerman, 1991; Suzuki et al., 1991; Sano et al., 1993; Sugimoto et al., 1996; Shibata et al., 1997).

The morphology of cadherin-based adherens junctions is remarkably similar to that of synapses (Peters et al., 1991). Consistent with this, $\mathrm{N}$-cadherin is concentrated in isolated postsynaptic densities (Beesley et al., 1995) and is localized to synaptic junctional complexes, where it has been suggested that it is instrumental in the targeting and "locking in" of synaptic connections (Fannon and Colman, 1996; Uchida et al., 1996; Inoue and Sanes, 1997). These data strongly suggest that the underlying mechanisms by which pre- and postsynaptic membranes adhere to one another in the CNS may be the same as those that generate intercellular adhesion in other, non-neural tissues. According to this model (Fannon and Colman, 1996; Uchida et al., 1996), synaptic specificity is generated by the differential expression and distribution of cadherins.

In this study, using cultured hippocampal neurons as a model system, we determine when cadherins become associated with synapses, whether they are present at all synapses, and whether $\mathrm{N}$-cadherin segregates to excitatory or inhibitory synaptic sites. The advantage of this system is that neurons can be grown at a very low density such that neuronal somata and dendrites are often completely isolated from one another and synapses and their subcellular distribution can be readily resolved by conventional light or confocal microscopy (Goslin and Banker, 1991). Our results indicate that early in synaptogenesis, N-cadherin is present at all synapses between hippocampal neurons but rapidly becomes restricted to excitatory synapses, a distribution that is maintained in mature brain in vivo. 


\section{MATERIALS AND METHODS}

Neuron cultures. Cell cultures were prepared from hippocampi of embryonic day 18 Sprague Dawley rats as described previously (Goslin and Banker, 1991; Benson et al., 1994). Cells were dissociated by treatment with $0.25 \%$ trypsin for $15 \mathrm{~min}$ at $37^{\circ} \mathrm{C}$ followed by trituration through a Pasteur pipette. Cells were plated at a density of $3600 \mathrm{cells} / \mathrm{cm}^{2}$ on poly-L-lysine-coated coverslips in minimum essential media (MEM; Life Technologies, Gaithersburg, MD) containing 10\% horse serum. After $\sim 4 \mathrm{hr}$, when cells had attached, coverslips were transferred to dishes containing a monolayer of cortical astroglia, where they were maintained for up to 5 weeks in MEM containing $\mathrm{N}_{2}$ supplements (Bottenstein and Sato, 1979), sodium pyruvate $(1 \mathrm{~mm})$, and ovalbumin $(0.1 \%)$.

Immunoblots and antibody controls. The $\mathrm{N}$-cadherin and $\beta$-catenin antibodies used in this study had not been characterized previously in rat brain. Homogenates were prepared from hippocampal neurons that had been grown in culture for 3 weeks by rinsing cells in PBS and then solubilizing them in homogenization buffer containing $20 \mathrm{~mm}$ tetrasodium pyrophosphate, $20 \mathrm{~mm}$ sodium phosphate, $1 \mathrm{~mm}$ magnesium chloride, $0.5 \mathrm{~mm}$ EDTA, $300 \mathrm{mM}$ sucrose, $8 \mu \mathrm{M}$ benzamidine, $10 \mu \mathrm{M}$ iodoacetamide, $0.011 \mu \mathrm{M}$ leupeptin, $0.007 \mu \mathrm{M}$ pepstatin A, $0.23 \mathrm{~mm}$ PMSF, and $76.8 \mathrm{~nm}$ aprotinin. Samples were sonicated briefly, centrifuged for $5 \mathrm{~min}$ at maximum speed on a microfuge, and stored at $-20^{\circ} \mathrm{C}$. Thawed samples $(5 \mu \mathrm{g})$ were fractionated on $7.5 \%$ SDS-polyacrylamide gels and transferred to polyvinylidene difluoride paper. Blots were incubated with either mouse monoclonal anti-N-cadherin, an antibody directed against the $\mathrm{C}$-terminal intracellular domain of $\mathrm{N}$-cadherin (13A9; gift from $\mathrm{K}$. Knudsen Lakenau Medical Research Center) (Knudsen et al., 1995), or mouse anti- $\beta$-catenin (Zymed, San Francisco, CA).

Immunostaining. Immunostaining was performed as described previously (Benson et al., 1994) using the following primary antibody(ies) diluted in $1 \%$ BSA in PBS at $4^{\circ} \mathrm{C}$ overnight: guinea pig polyclonal or mouse monoclonal anti-N-cadherin; anti-GAD65 (monoclonal antibody GAD6; Developmental Studies Hybridoma Bank) (Chang and Gottlieb, 1988); anti-synaptophysin [Boehringer Mannheim, Indianapolis, IN (mouse) or Zymed (rabbit)]; anti-MAP2 (monoclonal antibody AP14; gift from E. Torre, University of Virginia) (Binder et al., 1986); antiphosphorylated NF-H/M (monoclonal antibody SMI-31; Sternberger Monoclonals, Baltimore, MD); anti- $\beta$-catenin (Zymed); and antiGluR1 and anti-postsynaptic density (PSD)-95 (Upstate Biotechnology, Lake Placid, NY).

Antibody binding was visualized by incubating cells either with a biotinylated secondary antibody, followed by fluorescein-labeled streptavidin (both from Vector Laboratories, Burlingame, CA), or with Texas Red-labeled secondary antibodies (Vector Laboratories). For all studies in which two antibodies were used simultaneously, staining was compared with that obtained in cultures that were incubated with a single primary antibody and with cultures incubated with different combinations of secondary antibodies.

Mice were deeply anesthetized and then perfused transcardially with 4\% paraformaldehyde in PBS as described previously (Benson et al., 1992). A tissue block from monkey hippocampus was kindly provided by J. Morrison (Mount Sinai School of Medicine). Sections were cut on a vibratome at a setting of $50 \mu \mathrm{m}$, and free-floating sections were processed for immunocytochemistry as described above.

Microscopy and analysis. Localization of immunocytochemically identified proteins was assessed by conventional or confocal microscopy. For confocal microscopy, both single optical sections and "compressed" series (projections) of $z$-axis optical sections were used to compare localization of two labels. Most of the data are presented as projections of 3-30 optical sections (3-9 sections through processes and 16-30 through somata) varying in width from 0.1 to $0.5 \mu \mathrm{m}$. Figure legends indicate single sections as well as variations in these parameters. Data obtained from two channels simultaneously using a dichroic beam splitter were compared with data obtained sequentially using one laser line to ensure that emission spectra were clearly separated. Colocalization was assessed on two different confocal microscopes: a Zeiss LSM 410 using a $63 \times, 1.4$ numerical aperture (NA) oil immersion objective, an $\mathrm{Ar} / \mathrm{Kr}$ laser, a red-reflecting dichroic beam splitter, and filters $\lambda 575-640$ and $\lambda 515-540$, and a Leica TCS 4D using a $100 \times, 1.4$ NA oil immersion objective, an $\mathrm{Ar} / \mathrm{Kr}$ laser, a red-reflecting dichroic beam splitter, and filters BPFITC and OG590. The degree to which the labels offset one another by error intrinsic to the microscope was determined in N-cadherin-immunolabeled preparations simultaneously tagged with FITC and Texas Red. By the use of the Zeiss confocal, green was offset from red 1 pixel at an angle of $\sim 45^{\circ}$ in single images and 0.5 pixel at the same angle in projected images. By the use of the Leica confocal, there was a fraction of a pixel offset at $135^{\circ}$ that could be detected in both single and projected images Given the far greater degree of pixel overlap when comparing colocalization of two labels, the image overlap was not altered post hoc. Brightness and contrast settings for each label in double-labeled preparations were kept within close range of one another. The area of labeled puncta was measured using National Institutes of Health Image. Threshold intensity was set to include for measurements only puncta. Although user-determined thresholds for quantitative analysis might be expected to yield a high degree of variability, we have found "thresholded" data to be very consistent (Gazzaley et al., 1997).

GAD and $\mathrm{N}$-cadherin codistribution was quantified on at least 10 neurons from two preparations at each time point presented. GAD and $\mathrm{N}$-cadherin immunoreactive puncta were mapped separately on single neurons using a $63 \times$ oil immersion objective on a Zeiss Axiophot (conventional) microscope, and the maps were aligned using NeuroZoom (a set of software programs for quantitative microscopy developed via a collaboration between Scripps Research Institute and Mount Sinai School of Medicine).

\section{RESULTS}

\section{Localization and specificity of $\mathrm{N}$-cadherin and $\beta$ -} catenin antibodies in rat hippocampal neurons

In immunoblots from homogenates of cultured rat hippocampal neurons, mouse $\mathrm{N}$-cadherin antibody identified a single band of $\sim 130 \mathrm{kDa}$, and $\beta$-catenin antibody identified a single band of $\sim 100 \mathrm{kDa}$, similar to what has been described for the identification of each protein in other species or with different antibodies (Fig. 1A). In cultured neurons, immunocytochemical localization of mouse $\mathrm{N}$-cadherin was compared directly with localization of a guinea pig polyclonal $\mathrm{N}$-cadherin antibody in double-labeled preparations. Polyclonal antibody labeling was more intense than monoclonal, but the two labels overlapped completely (Fig. $1 B, C)$. When $\mathrm{N}$-cadherin polyclonal antibody was preincubated with a peptide fragment corresponding to the domain against which it was made, all specific labeling was eliminated (Fig. $1 D-G)$. Together these data indicate that the $\mathrm{N}$-cadherin and $\beta$-catenin antibodies used in this study were completely specific.

\section{$\mathbf{N}$-cadherin is localized to developing synapses}

Hippocampal neurons cultured at low density were used to examine the localization of $\mathrm{N}$-cadherin at the earliest stages of neuron development and synapse formation. Before axonal outgrowth, diffuse $\mathrm{N}$-cadherin labeling was observed in cell somata and minor processes that also contained small, immunoreactive puncta (Fig. 2A). After axonal outgrowth (12-36 hr after plating), $\mathrm{N}$-cadherin-labeled puncta were more abundant in axons that could be identified by their longer length and finer caliber, but diffuse $\mathrm{N}$-cadherin labeling remained in both cell somata and young dendrites (Fig. 2D,F). Identification of axons was confirmed in some preparations by coimmunolabeling cultures with an axonal marker SMI-31 that recognizes phosphorylated neurofilament triplet proteins (data not shown). N-cadherin puncta were only occasionally concentrated within axonal growth cones where they lined the leading edge of lamellipodia but did not invade filopodia (Fig. 2G). Thus, N-cadherin is present within both pre- and postsynaptic compartments before synapses develop, and the diffuse labeling may represent a locally recruitable pool of cadherins that would be rapidly accessible for junction formation (Colman, 1997).

The relationship of $\mathrm{N}$-cadherin puncta to synapses was determined in neurons double-immunolabeled for $\mathrm{N}$-cadherin and synaptophysin, a synaptic vesicle protein concentrated in presynaptic terminals (Navone et al., 1989; Fletcher et al., 1994). Before synapse formation (the first $2 \mathrm{~d}$ in culture), synaptophysin-labeled 


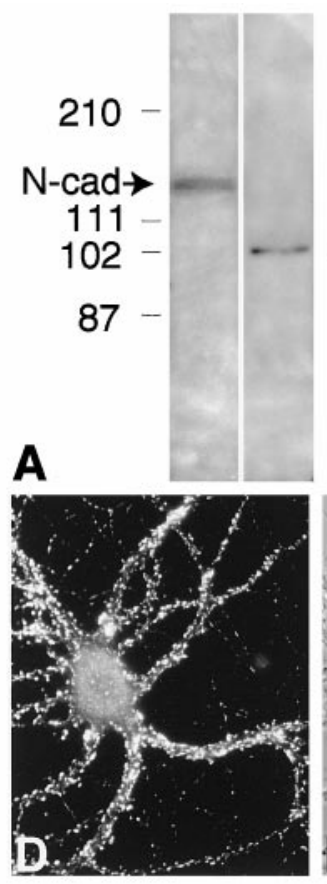

Figure 1. Localization and specificity of $\mathrm{N}$-cadherin and $\beta$-catenin antibodies. $A$, Western blots of homogenates from 17-dold cultured hippocampal neurons incubated with monoclonal antibody against $\mathrm{N}$-cadherin $(N$-cad; left $)$ or $\beta$-catenin $(\beta$ cat; right) are shown. Size standards are indicated on the left. $B, C$, Extracellular $(B)$ and intracellular $(C)$ domain-specific antibodies against $\mathrm{N}$-cadherin colocalize in double-immunolabeled preparations of cultured hippocampal neurons. $D, F$, Preadsorbed polyclonal antibody yields no specific immunolabeling $(F)$ compared with control $(D)$. $E, G$, Corresponding phase-contrast photomicrographs are shown. Scale bars: $B, C, 4 \mu \mathrm{m}$; $D-G, 35 \mu \mathrm{m}$.

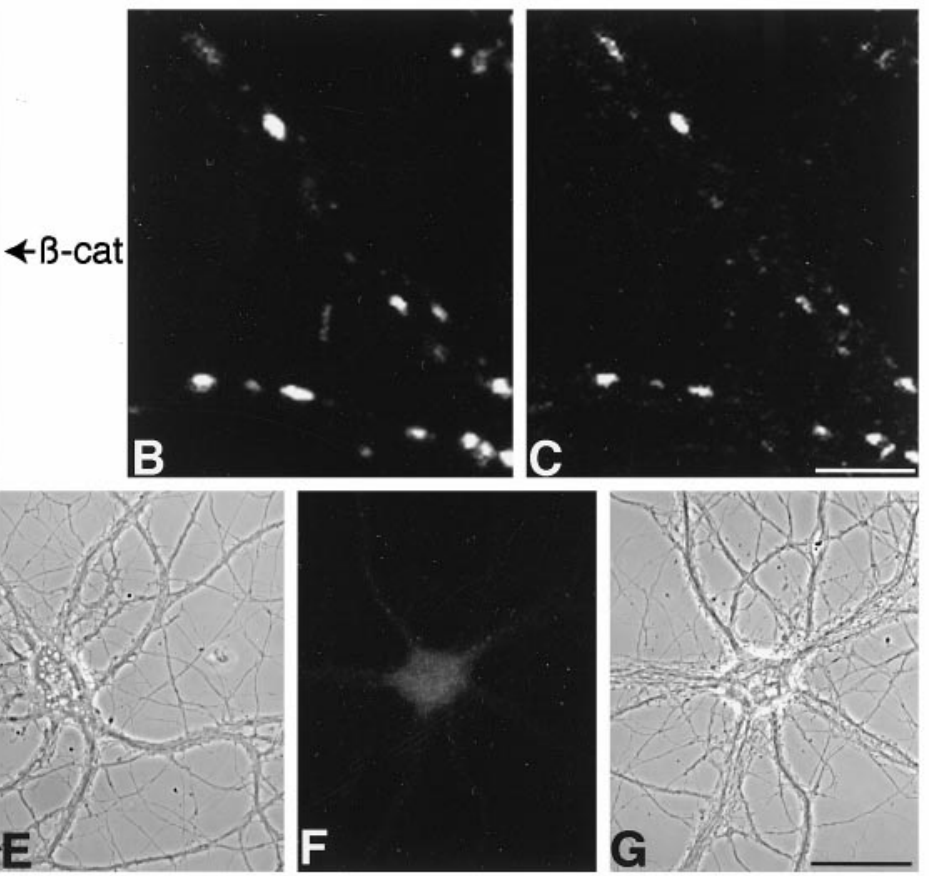

vesicles did not appear to be localized particularly with $\mathrm{N}$-cadherin puncta (Fig. $2 B, E$ ), but at the onset of synaptogenesis ( $3 \mathrm{~d}$ in culture), synaptophysin-labeled clusters were colocalized with $\mathrm{N}$-cadherin-labeled puncta (Fig. $3 A-C$ ), and cytoplasmic $\mathrm{N}$-cadherin labeling rapidly disappeared. In high magnification confocal images, there was most commonly a central region of colocalization flanked on one side by a rim of synaptophysin label and on the other by a rim of N-cadherin label. The area occupied by $\mathrm{N}$-cadherin puncta appeared to be larger than that occupied by synaptophysin boutons (Fig. 3C, inset), but the difference was not significant $(p=0.34)$. Nearly all $\mathrm{N}$-cadherin puncta were labeled for synaptophysin, and those puncta lacking synaptophysin were very small, similar to those seen before synaptogenesis, and were presumed to be nonsynaptic puncta adherens. Synaptophysin accumulations clearly smaller than those that were "synaptic" (Fletcher et al., 1991) lacked N-cadherin.

Between 1 and 2 weeks in culture, an increasing number of synaptophysin-labeled boutons lacked corresponding $\mathrm{N}$-cadherin puncta, but the vast majority of N-cadherin-labeled puncta continued to be colocalized with synaptophysin (Fig. 3D-F). Singleand double-labeled puncta were distributed along single dendrites. In projected confocal images, a clear pattern of colocalization emerged. The area occupied by $\mathrm{N}$-cadherin puncta was significantly larger than that occupied by synaptophysin boutons $\left(0.44 \pm 0.03\right.$ vs $\left.0.28 \pm .04 \mu \mathrm{m}^{2} ; p<0.005\right)$, and the region of colocalization with synaptophysin occurred over a central common zone. The range of configurations varied, but in all cases examined and through all angles of rotation, N-cadherin label appeared to overlap and usually surround synaptophysin-labeled clusters (Fig. 3D-J). Synaptophysin boutons lacking $\mathrm{N}$-cadherin were easily distinguished even when they occurred close to $\mathrm{N}$-cadherin puncta (Fig. 3I,J). The most likely interpretation for this localization pattern is that $\mathrm{N}$-cadherin and synaptophysin are colocalized in the presynaptic side of the synaptic junctional complex and that N-cadherin is also distributed postsynaptically (see also Fig. 7). Together, these data indicate that in hippocampal neurons all early synapses are associated with $\mathrm{N}$-cadherin, but after $7 \mathrm{~d}$, a growing population of synapses lose $\mathrm{N}$-cadherin and/or develop in the absence of $\mathrm{N}$-cadherin.

\section{$\mathrm{N}$-cadherin is lost from inhibitory synapses but retained at excitatory synapses in culture and in situ}

To investigate whether N-cadherin-negative and -positive synapses in older cultures corresponded to inhibitory and excitatory synapses, we double-immunolabeled neurons for $\mathrm{N}$-cadherin and markers for inhibitory (GABAergic) and excitatory (glutamatergic) synapses, which together comprise the entire repertoire of synaptic interactions found in cultured hippocampal neurons.

GABAergic synaptic boutons were identified using antibodies against glutamic acid decarboxylase (GAD) (Ribak, 1978; Benson et al., 1994; Benson and Cohen, 1996). Up to $7 \mathrm{~d}$ in culture, nearly all GAD-labeled boutons contained N-cadherin (Fig. 4A-D). At high magnification, $\mathrm{N}$-cadherin puncta and GAD-labeled boutons colocalized over a large central region similar to what was observed for $\mathrm{N}$-cadherin and synaptophysin at early ages (compare Figs. $4 B-D, 3 A-C$ ). However, after $7 \mathrm{~d}$, the number of GAD- and $\mathrm{N}$-cadherin-labeled boutons declined such that, by $17 \mathrm{~d}$, virtually no GAD-labeled boutons contained detectable N-cadherin (Fig. $4 E-H)$. The timing of this shift in N-cadherin localization was determined by calculating the percentage of GABAergic synapses containing $\mathrm{N}$-cadherin label for at least 10 neurons in two culture preparations at several time points (Fig. 5). The results indicate that, surprisingly, $\mathrm{N}$-cadherin is present at all early synapses but becomes rapidly and selectively restricted to non-GABAergic and therefore excitatory synapses. Early GABAergic synapses associated with $\mathrm{N}$-cadherin must be selectively eliminated, or $\mathrm{N}$-cadherin must be removed from GABAergic synapses. Interestingly, at intermediate time points, very faint $\mathrm{N}$-cadherin label was occasionally detected at some GABAergic synaptic sites. These synapses were counted as $\mathrm{N}$-cadherin negative because the labeling intensity was too low to detect using thresholds similar to those used for the area measurements described above but may represent a transitional state in which $\mathrm{N}$-cadherin is gradually lost from GABAergic synapses. 

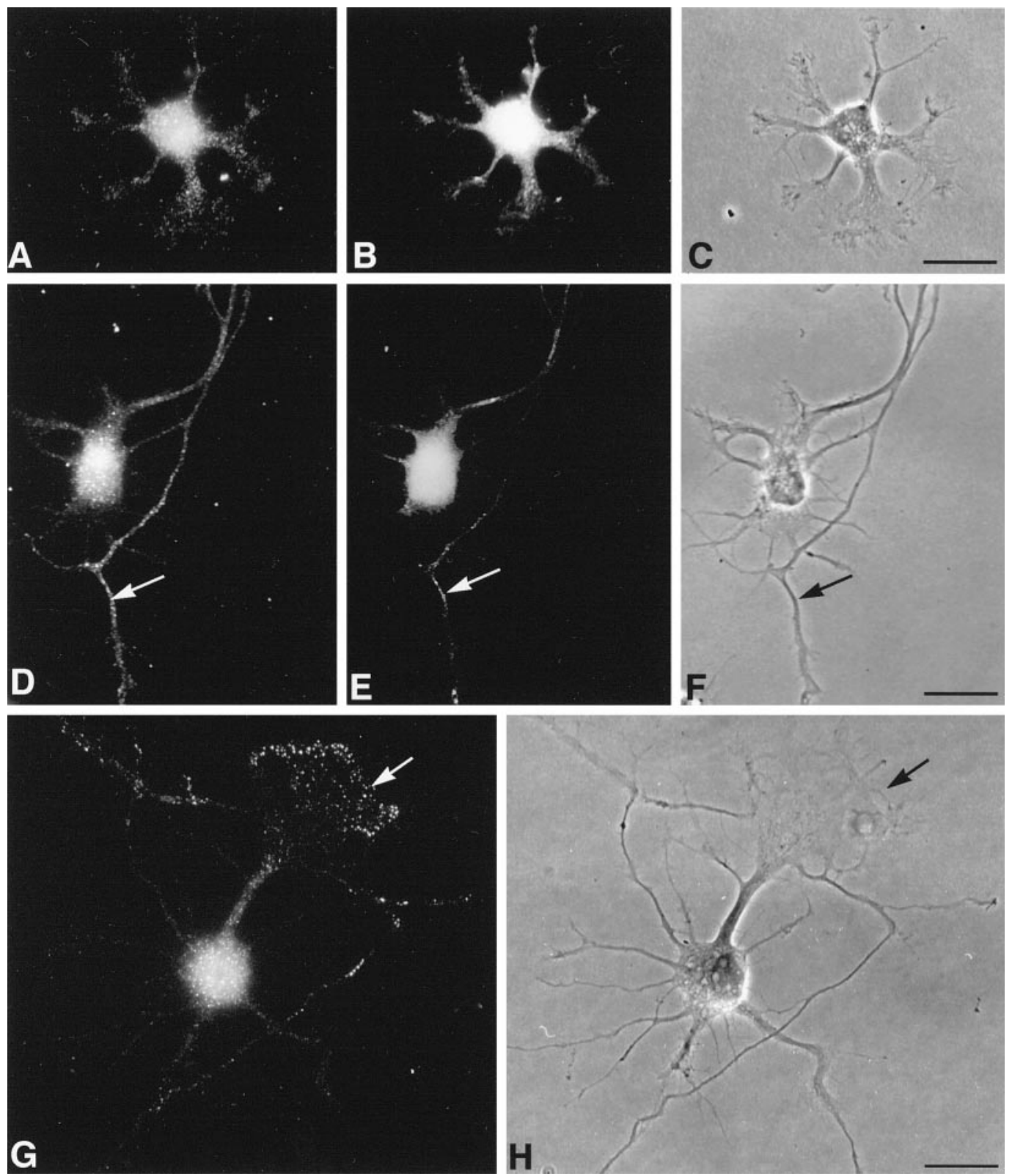

Figure 2. N-cadherin is present in axons and dendrites before synaptogenesis. Fluorescence photomicrographs showing N-cadherin $(A, D, G)$ and synaptophysin $(B, E)$ immunolabeling alongside corresponding phase-contrast photomicrographs $(C, F, H)$ during early stages of neuron development are shown. Before axonal outgrowth, N-cadherin- $(A)$ and synaptophysin- $(B)$ labeled puncta are distributed throughout the cell soma and minor processes $(C)$. After polarization, N-cadherin labeling $(D)$ is detected in both the axon (arrow) and dendrites, whereas in the same neuron, synaptophysin labeling is polarized to the axon (E; arrow). Both labels are detected in soma $(D, E)$. In $G$ and $H$, N-cadherin is concentrated at the lamellipodial edge of a particularly large growth cone (arrow). Scale bars: $A-F, 18 \mu \mathrm{m} ; G, H, 11 \mu \mathrm{m}$.

The double-labeling experiments strongly suggest that $\mathrm{N}$-cadherin in older neurons is associated with asymmetric, glutamatergic synapses. To address this, we double-immunolabeled neurons $17 \mathrm{~d}$ or older for $\mathrm{N}$-cadherin and PSD-95/SAP90, a membrane-associated guanylate kinase concentrated within asymmetric postsynaptic densities in forebrain (Hunt et al., 1996), or GluR1, an AMPA-type glutamate receptor subunit that clusters opposite glutamate terminals (Craig et al., 1994). N-cadherin puncta were associated with both PSD-95-labeled densities and with GluR1-labeled clusters (Fig. 6), many of which were localized on dendritic spines. Some N-cadherin puncta were unlabeled in both cases. Most PSD-95-labeled densities but not all GluR1labeled clusters were labeled for $\mathrm{N}$-cadherin. Thus, $\mathrm{N}$-cadherin labeling is associated with postsynaptic as well as with presynaptic markers and appears to be concentrated at a population of asymmetric, excitatory synapses some of which are located on dendritic spines and may represent a distinct excitatory synapse type or functional state.

To examine whether the absence of N-cadherin from GABAergic pathways was a general phenomenon in mature brain, we double-immunolabeled sections from mouse, rat, and monkey brain for $\mathrm{N}$-cadherin and GAD and examined the sections by confocal microscopy. Localization in hippocampal region CA3 revealed most dramatically the differential distribution: $\mathrm{N}$-cadherin puncta were restricted to stratum lucidum, a layer receiving almost exclusively glutamatergic mossy fiber input aris- 

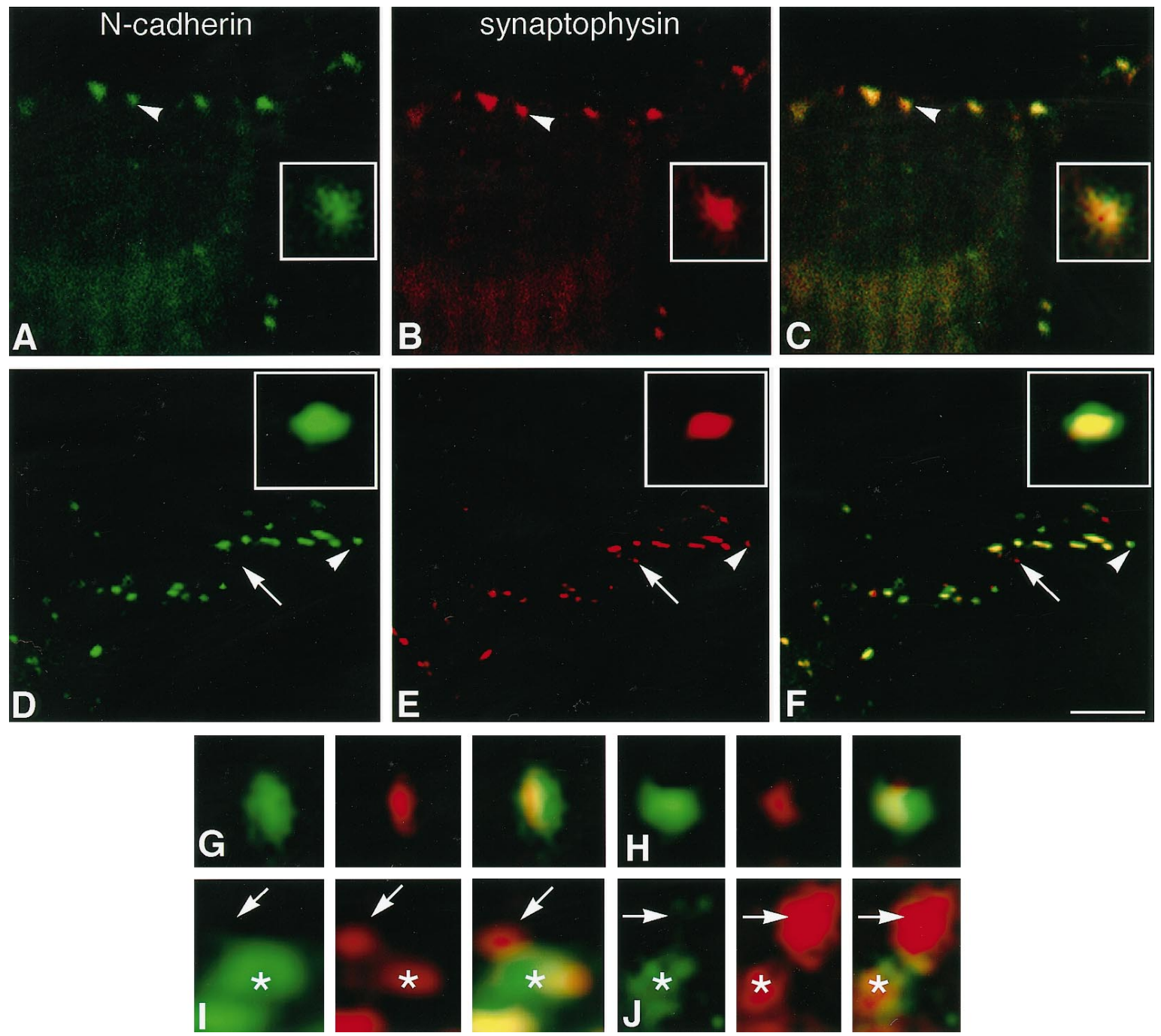

Figure 3. Synaptic localization of N-cadherin. Confocal images show N-cadherin ( green) and synaptophysin (red) immunolabeling separately and overlaid in which regions of colocalization that appear yellow. $A-C$, In 5-d-old neurons, single optical sections show all N-cadherin-labeled puncta $(A$; green) contain synaptophysin label $(B ; r e d)$. When images are overlaid $(C)$, the close association of $\mathrm{N}$-cadherin and synaptophysin is readily apparent with each complex having a central area of colocalization (yellow). The synaptic complex (indicated by the arrowhead) is presented at higher magnification in each inset. $D-F$, By $14 \mathrm{~d}$, most N-cadherin puncta ( $D$; green) remain associated with synaptophysin boutons $(E$; red), but some synaptophysin boutons (arrow) lack N-cadherin $(F)$. The larger size of green $\mathrm{N}$-cadherin puncta and their relationship with red synaptophysin-labeled boutons can be seen in the higher magnification inset of the synaptic complex (indicated by the arrowhead) in $D-F$ as well as in $G$ and $H$. $G-H$, N-cadherin appears to partially enclose synaptophysin labeling. I-J, Figures illustrate the differences between synaptophysin boutons that do not contain N-cadherin (arrows) but are close to those that are colocalized with N-cadherin (asterisks). Scale bars: $A-C, 4 \mu \mathrm{m}$ (insets, $1 \mu \mathrm{m}) ; D-F, 11 \mu \mathrm{m}$ (insets, $1 \mu \mathrm{m}) ; G, 1 \mu \mathrm{m} ; H, 1.3 \mu \mathrm{m}$; $I, 0.7 \mu \mathrm{m} ; J, 0.8 \mu \mathrm{m}$.

ing from dentate gyrus granule neurons, whereas GABAergic boutons were concentrated within the adjacent pyramidal cell layer with little overlap between the two zones (Fig. $7 A-C$ ). Similarly, N-cadherin puncta and GABAergic boutons did not appear to colocalize in any region examined including cerebral cortex, hippocampus, amygdala, habenula, dorsal thalamus, thalamic reticular nucleus, caudate-putamen, globus pallidus, and hypothalamus (Fig. $7 A-I$ ). Sections that were doubleimmunolabeled for $\mathrm{N}$-cadherin and synaptophysin indicated that the majority of $\mathrm{N}$-cadherin puncta were associated with synaptophysin (Fig. $7 F$ ).

\section{$\beta$-Catenin is concentrated at GABAergic synapses}

$\beta$-Catenin binding and clustering at cadherin intracellular domains are common to all classic cadherin-mediated junctions and are, in fact, required for adhesion (Ozawa et al., 1990; Gumbiner and McCrea, 1993; Peifer et al., 1993; Oyama et al., 1994; Haegel et al., 1995; Cox et al., 1996). In cells lacking cadherins, catenins never form clusters at sites of cell-cell contact (Kemler, 1993; Nakagawa and Takeichi, 1995). It follows that if cadherins are components of all synaptic junctional complexes, then GABAergic synaptic sites may contain $\beta$-catenin. To examine this, we double-immunolabeled 14-d-old neurons for GAD and $\beta$-catenin. Analysis by confocal microscopy showed that GAD-labeled boutons colocalized with $\beta$-catenin-labeled clusters, and similar to the localization of $\mathrm{N}$-cadherin and synaptophysin, $\beta$-catenin clusters partially overlapped with the presynaptic GAD label but extended over a greater area to what is likely to be the postsynaptic surface as well (Fig. $7 J-L$ ). These data suggest that although early GABAergic synaptic junctional complexes contain $\mathrm{N}$-cadherin, mature and late-forming GABAergic synaptic junc- 

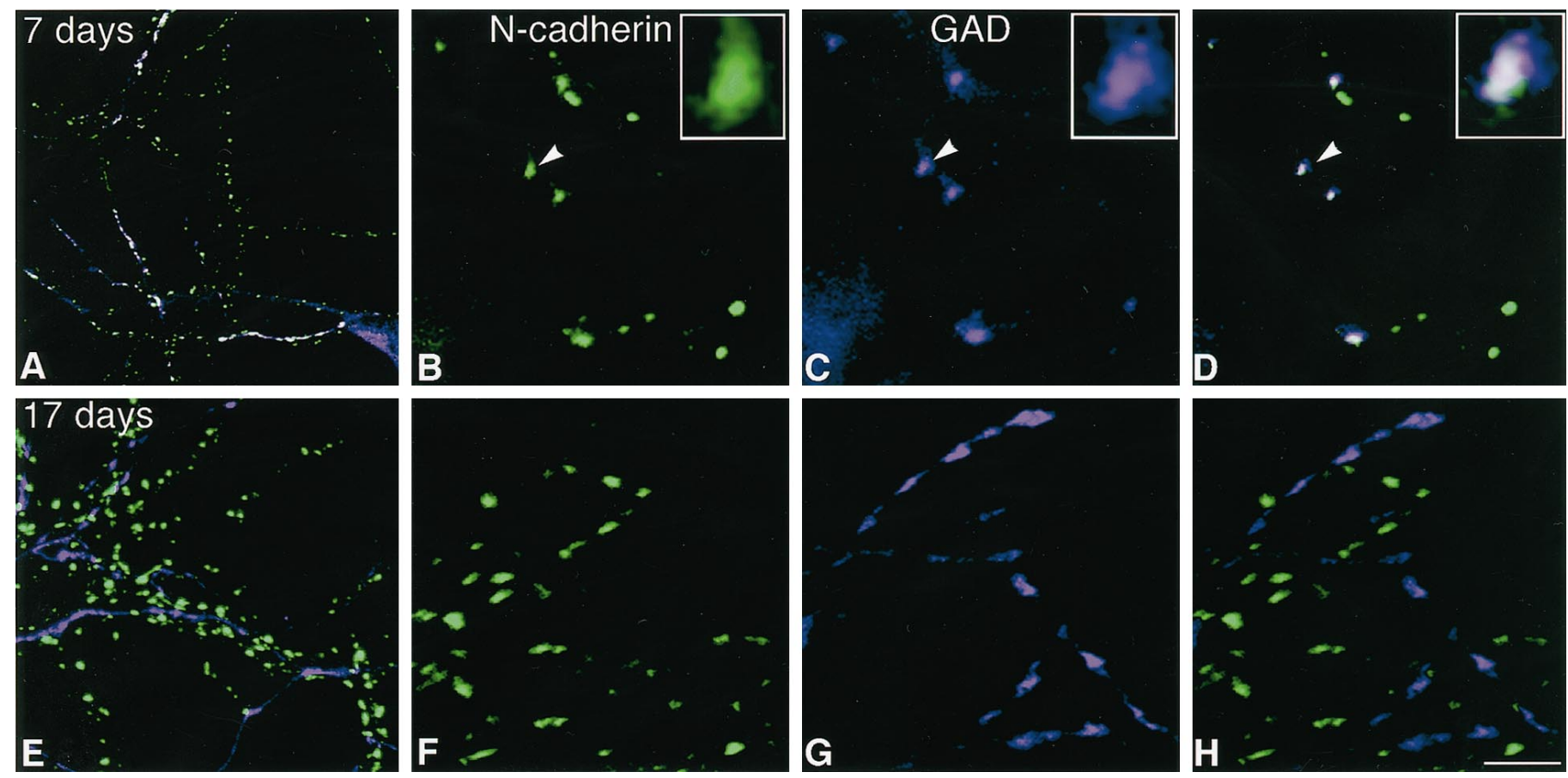

Figure 4. N-cadherin is lost from inhibitory synapses. Confocal images show low and high magnification images of N-cadherin (green) and GAD ( purple) immunolabeling separately and overlaid where regions of colocalization appear white. $A-D$, At $7 \mathrm{~d}$ in culture, low $(A)$ and high $(B-D)$ magnification images show all GAD-labeled boutons associated with N-cadherin puncta. Synaptic complex indicated by an arrowhead is shown at higher magnification in each inset $(B-D)$ where a large area of colocalization appears white in overlay. $E-H$, In contrast, both low $(E)$ and high $(F-H)$ magnification images indicate that by $17 \mathrm{~d}$ in culture no GAD-labeled synapses contain N-cadherin. Scale bars: $A, 25 \mu \mathrm{m} ; B-D, 5 \mu \mathrm{m}$ (insets, $1 \mu \mathrm{m}$ ); $E$, $12 \mu \mathrm{m} ; F-H, 7 \mu \mathrm{m}$.

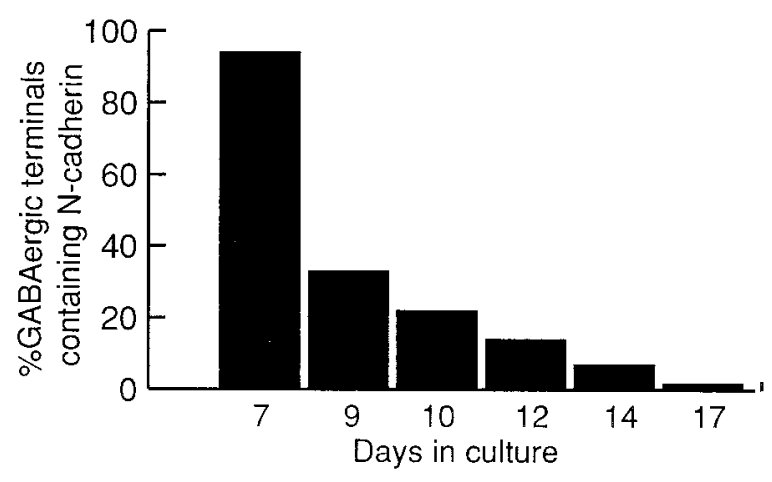

Figure 5. Rate of N-cadherin loss from GABAergic synaptic sites. The bar graph illustrates the percentage of GAD-labeled boutons containing $\mathrm{N}$-cadherin label at different stages of development. The percentage drops sharply between 7 and $9 \mathrm{~d}$ and then continues to drop more slowly to nearly zero by $17 \mathrm{~d}$ in culture.

tional complexes do not but are likely to contain another as yet unidentified cadherin. Thus, cadherins may be required for the formation or stabilization of both excitatory and inhibitory synaptic junctional complexes, but different cadherins are highly likely to be preferentially incorporated into each.

\section{$\beta$-Catenin in neurons is both synaptic and nuclear}

Cadherin-mediated adhesion is accompanied by $\beta$-catenin clustering at adhesion sites. To determine whether the synaptic clustering of cadherins was in fact adhesive as well as to further examine the potential role of cadherins during synapse assembly, we compared the immunolocalization of $\beta$-catenin with that for
$\mathrm{N}$-cadherin and synaptophysin before and during synaptogenesis. In general, most $\beta$-catenin labeling was found in puncta that were smaller and more broadly distributed than $\mathrm{N}$-cadherin puncta and that frequently were concentrated in larger clusters, similar to what has been described by Uchida et al. (1996) in mouse brain. It was also found concentrated at sites of soma-soma contact. Interestingly, similar to what has been described within a number of developing as well as cancerous tissues, $\beta$-catenin was found within nearly all neuronal nuclei (Fig. $8 A, B$ ). Nuclear label was distributed throughout the nucleoplasm and was not observed within nucleoli. These data suggest that in addition to its actions associated with cadherin-based adhesion at the cell surface, neuronal $\beta$-catenin is likely to participate in a cytoplasm-to-nucleus signaling pathway similar to what has been described in other systems (Gumbiner, 1997; Shapiro, 1997).

The developmental localization of $\beta$-catenin labeling was similar to that for $\mathrm{N}$-cadherin in that it was polarized somewhat to axons and usually found in axonal growth cones, but not concentrated there (Fig. $8 C, D$ ). At all stages of synapse formation, clusters of $\beta$-catenin puncta corresponded to synapses (Fig. $8 E, F)$, and $\mathrm{N}$-cadherin puncta were associated with $\beta$-catenin clusters (Fig. $8 G-I$ ). $\beta$-Catenin puncta were observed at other sites, but the largest $\beta$-catenin clusters often corresponded to $\mathrm{N}$-cadherin sites (Fig. 8I). These data indicate that cadherins and $\beta$-catenin are associated with synapses from the time at which synaptophysin concentrations can first be detected, suggesting that cadherins are likely to be integral components of all developing synaptic junctional complexes. Furthermore they support the idea (Peters et al., 1991; Fannon and Colman, 1996; Uchida et al., 1996) that cadherin interactions at synapses are similar to those at adherens junctions. 

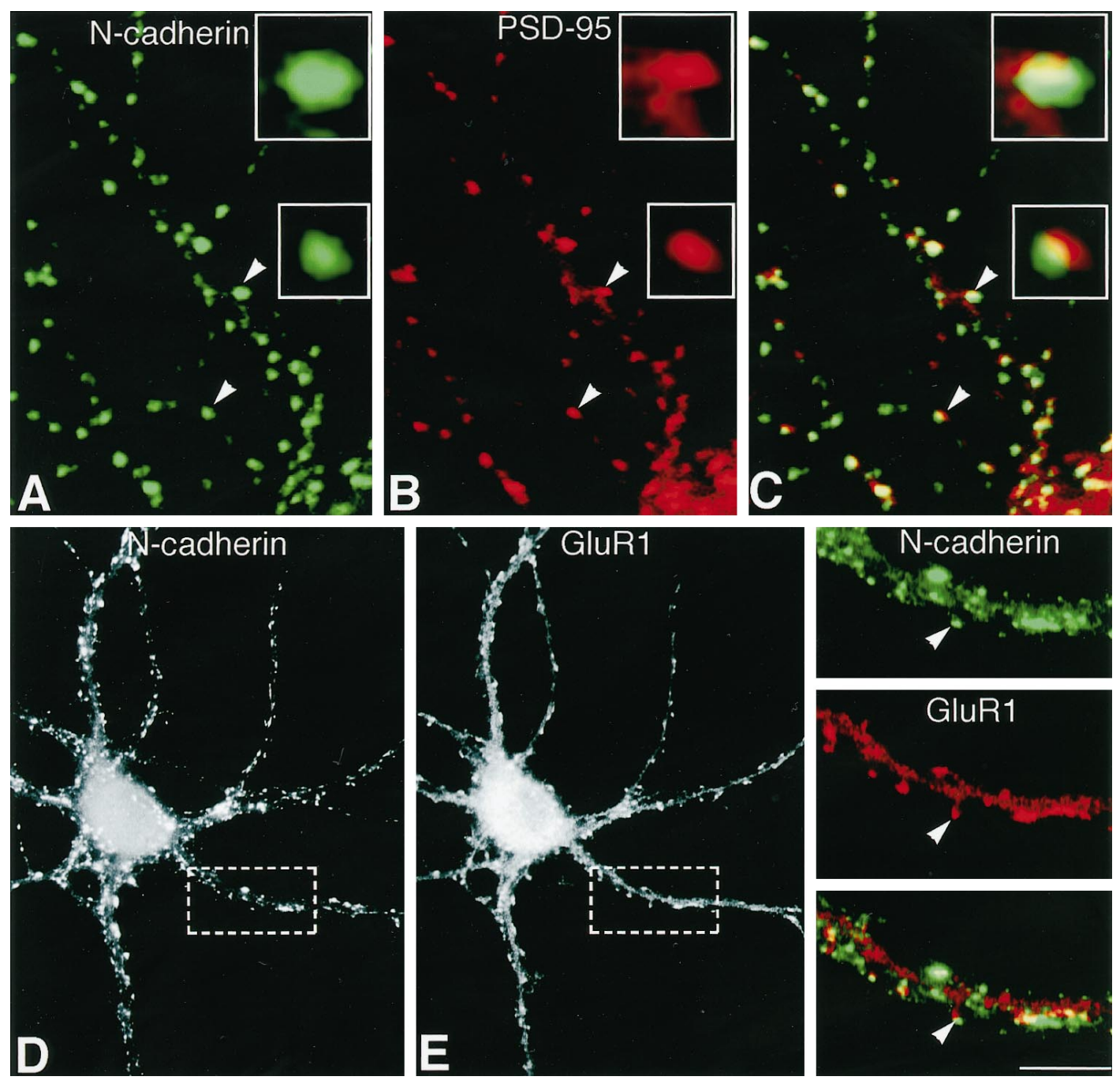

Figure 6. N-cadherin is associated with excitatory postsynaptic densities. Confocal images $(A-C)$ and fluorescence photomicrographs $(D, E)$ of cultured hippocampal neurons show colocalization of N-cadherin ( $D$; green) with the excitatory postsynaptic markers PSD-95 (B, $C$; red) and GluR1 (E; red). $A-C$, In 29-d-old neurons, in single optical sections, most N-cadherin puncta cluster at PSD-95-containing postsynaptic densities, some of which are on dendritic spines. Those indicated by upper and lower arrowheads in $A-C$ are shown at higher magnification in the upper and lower insets, respectively. $D$, $E, \mathrm{~N}$-cadherin puncta in 17-d-old neurons also associate with GluR1 clusters. Boxed regions are shown at higher magnification in color (red, green, and overlay) on the right where the arrowhead illustrates a double-labeled dendritic spine. Scale bars: $A-C, 7.5 \mu \mathrm{m}($ insets, $1.7 \mu \mathrm{m}) ; D, E$, $18 \mu \mathrm{m}$, higher magnification, $6 \mu \mathrm{m}$.

\section{DISCUSSION}

It has been suggested that the differential distribution of selected cadherins is responsible for linking up and locking in pre- and postsynaptic membranes of synaptic junctional complexes (Fannon and Colman, 1996). Findings of the present study support this contention. In cultured hippocampal neurons, $\mathrm{N}$-cadherin is expressed initially at all synaptic sites, excitatory and inhibitory, from the time at which synapses are first detected. However, although $\mathrm{N}$-cadherin is maintained at glutamatergic synaptic sites as the system matures, it is rapidly lost from GABAergic synaptic sites. GABAergic synapses appear to contain another as yet unidentified cadherin, insofar as they all associate with $\beta$-catenin, an obligatory binding partner of the classic cadherins. Together our findings indicate that cadherins may stabilize the earliest synaptic contacts and, more importantly, that N-cadherin is the first cell-cell adhesion molecule thus far described that differentiates between functionally distinct synaptic types (excitatory and inhibitory) that have different morphologies across their adhesive face (asymmetric and symmetric). Thus, in addition to neurotransmitters and receptors, synapses can be distinguished by distinct sets of scaffolding proteins. These findings suggest that in hippocampus, $\mathrm{N}$-cadherin adhesion may represent a critical step in synapse formation, after which a number of cadherins may become differentially targeted to specific synapse sites and serve to refine and restrict synaptic connectivity.

\section{Cadherins distinguish functionally distinct synaptic sites}

Our results indicate that $\mathrm{N}$-cadherin is concentrated at excitatory synaptic sites in mature hippocampal neurons in culture and in vivo and is not associated with inhibitory synaptic sites in a number of brain regions. $\mathrm{N}$-cadherin is also found within cerebellar mossy fiber terminals (Fannon and Colman, 1996) and in retinotectal projections, (Yamagata et al., 1995; Uchida et al., 1996; Wöhrn et al., 1998), both of which use glutamate as their neurotransmitter. Taken together, the data suggest that 

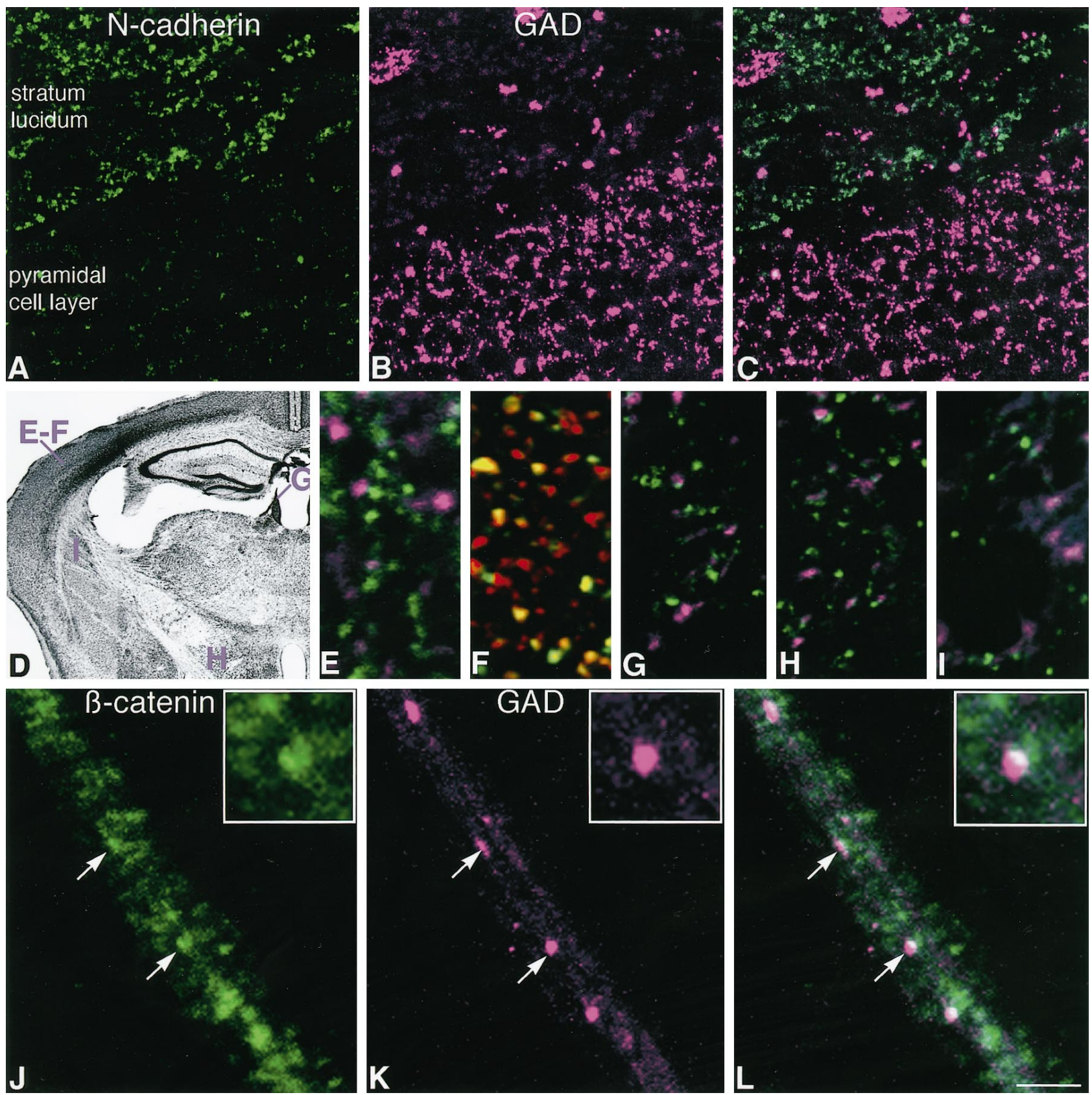

Figure 7. GABAergic synapses do not contain N-cadherin, but they do contain $\beta$-catenin. $A-I$, Confocal images and a bright-field photomicrograph of sections from adult brain double-labeled for N-cadherin ( green) and GAD ( purple) or synaptophysin (red) or stained for Nissl $(D)$. Sections through the CA3 region of monkey hippocampus $(A-C)$ show N-cadherin concentrated in mossy fiber terminals in stratum lucidum, whereas GABAergic terminals are concentrated in the pyramidal cell layer. Letters on Nissl-stained mouse brain section $D$ correspond to regions from semiadjacent sections shown at high magnification in $E-I$. In single optical sections through layers II and III of cerebral cortex, GABAergic synapses ( purple) do not contain $\mathrm{N}$-cadherin (green) $(E)$, but most N-cadherin puncta (green) are synaptophysin immunoreactive (red) and appear yellow $(F)$. Differential distribution of GAD and N-cadherin is also observed in single optical sections through the habenula $(G)$, hypothalamus $(H)$, and caudate-putamen $(I)$. $J-L$, Confocal images taken from 14-d-old cultured rat hippocampal neurons show $\beta$-catenin (green) and GAD ( purple) immunolabeling separately ( $J$, $K$ ) and overlaid $(L)$ where regions of colocalization appear white. Each purple GAD-labeled bouton associates with green $\beta$-catenin-labeled clusters (e.g., arrows). The bouton indicated by the top arrow is shown at high magnification in the inset, where the two labels can be seen to colocalize over a central white area. Scale bars: $A-C, 17 \mu \mathrm{m} ; D, 1 \mathrm{~mm} ; E, F, 7 \mu \mathrm{m} ; G-I, 7.5 \mu \mathrm{m} ; J-L, 5.6 \mu \mathrm{m}$ (insets, $2.8 \mu \mathrm{m}$ ).

$\mathrm{N}$-cadherin may be a common component of glutamatergic synapses corresponding to a variety of different pathways. On the other hand, inhibitory synapses appear to contain a different cadherin (or cadherins) in that $\mathrm{N}$-cadherin is lost but $\beta$-catenin is retained at mature GABAergic synaptic sites in hippocampal neurons. In cerebellum, $\alpha-\mathrm{N}$-catenin, which binds to $\beta$-catenin, is also clustered at symmetric (inhibitory) synapses (Uchida et al., 1996). The localization of catenins to GABAergic sites is significant in that catenins do not cluster at sites of cell-cell contact in cells lacking cadherins (Kemler, 1993; Nakagawa and Takeichi, 1995). Although it remains possible that catenins cluster at GABAergic synapses by their interactions with a different family 

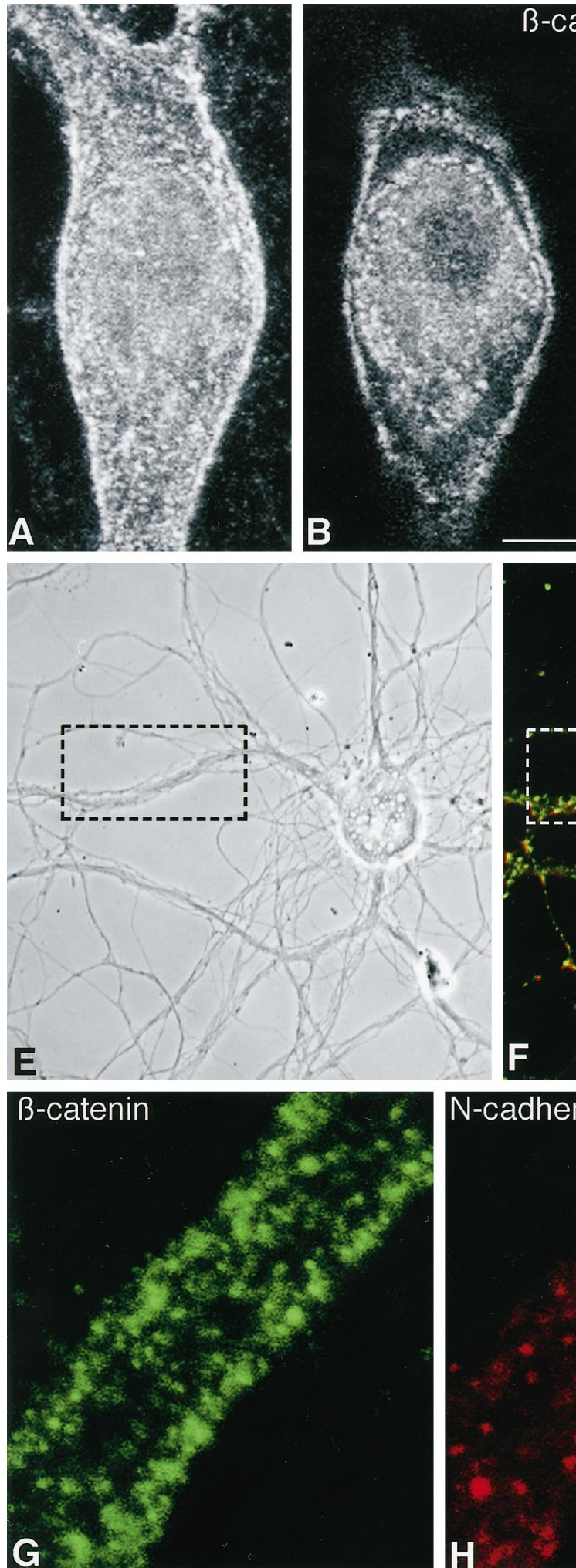
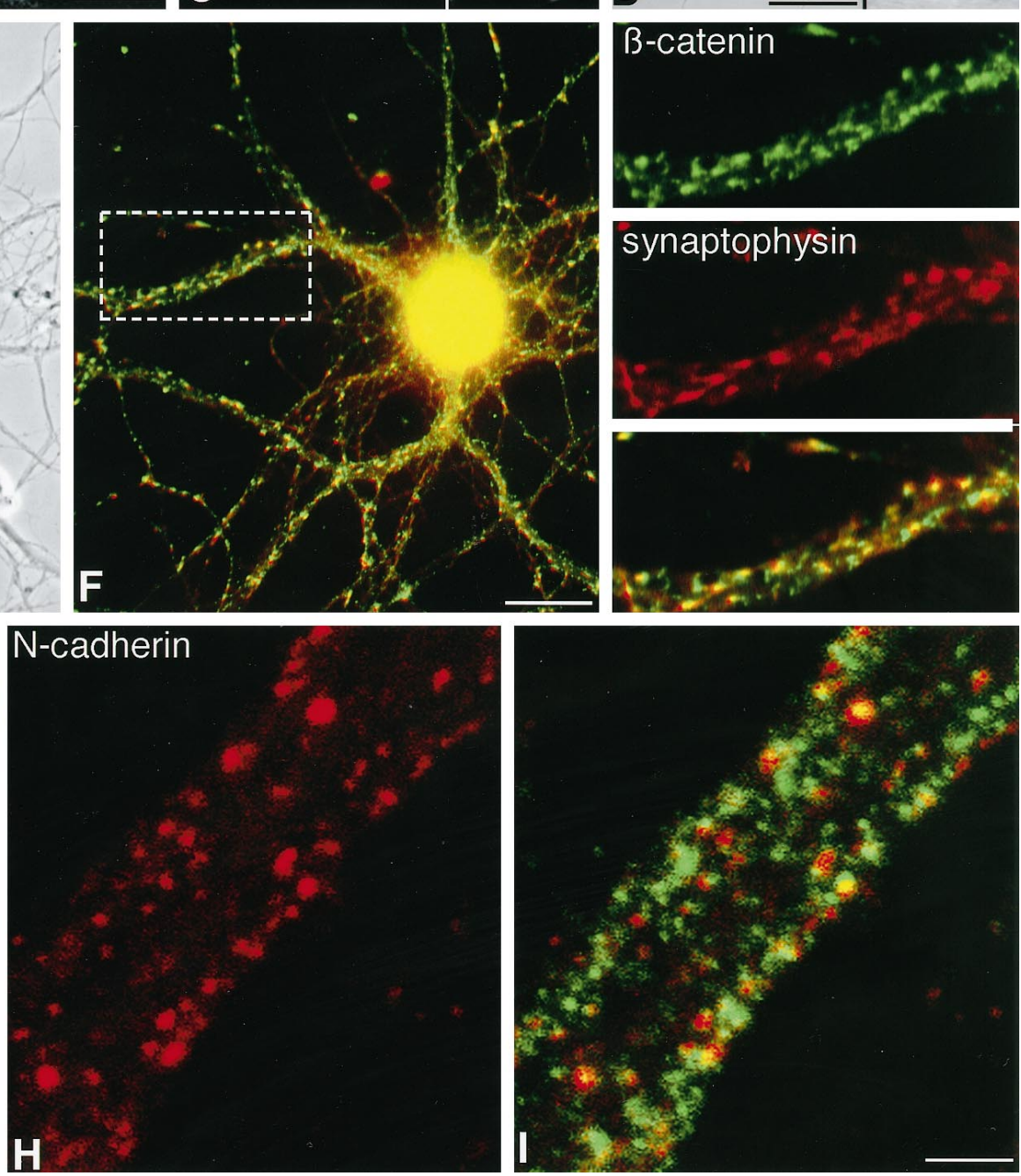

Figure 8. $\quad \beta$-Catenin is found at synapses and in nuclei. $A, B$, Projection of confocal images through an entire cell somata $(10 \times 1 \mu \mathrm{m})$ indicates both surface $\beta$-catenin labeling and label within the nucleus $(A)$, but projection of a subset of the same images $(3 \times 1 \mu \mathrm{m})$ emphasizes the nuclear distribution $(B)$. The nucleolus is unlabeled, and the nuclear envelope appears to be labeled in a punctate manner. $C, D$, Fluorescence and phase photomicrographs show $\beta$-catenin-labeled puncta in both axons and young dendrites before synapse formation. Although not concentrated particularly in growth cones, puncta are observed occasionally in filopodia (insets). E, $F, \beta$-Catenin-labeled puncta (green) colocalize with synaptophysin-labeled (red) synapses as shown in phase and fluorescence photomicrographs of 13-d-old cultured neurons. Boxed regions indicated in $E$ and $F$ are shown at higher magnification on the right separately and overlaid. $G-I$, In confocal images of 26-d-old neurons, N-cadherin-labeled puncta $(H ;$ red $)$ represent a subpopulation of $\beta$-catenin-labeled puncta $(G$; green $)$. Most of the large $\beta$-catenin puncta correspond to those labeled for N-cadherin $(G-I)$. Scale bars: $A, B, 6 \mu \mathrm{m} ; C, D, 27 \mu \mathrm{m}$ (insets, $6 \mu \mathrm{m}) ; E, F, 20 \mu \mathrm{m}$ (boxes, $10 \mu \mathrm{m}) ; G-I, 2 \mu \mathrm{m}$. 
of molecules, the most likely interpretation of our results is that, within individual neurons, cadherins can be targeted differentially to functionally distinct synaptic sites. In addition, populations of excitatory synapses may also be subdivided and grouped in single neurons because in culture most, but not all, contain $\mathrm{N}$-cadherin. Differentially expressed cadherins in brain have been hypothesized to serve as a basis for interconnecting functionally related areas, nuclei, and laminae (Redies et al., 1992; Arndt and Redies, 1996; Inoue and Sanes, 1997; Suzuki, 1997; Arndt et al., 1998). Our results extend this notion by suggesting that cadherin interactions may also be differentially mediated at synapses within single neurons.

\section{Cadherins and synaptic junctions}

Several lines of evidence indicate that cadherins and catenins are localized to synaptic junctional complexes (Serafini, 1997). Localization by electron microscopy suggests that cadherins and catenins can be concentrated within synaptic clefts or clustered in subsynaptic zones, often at the edges of synaptic junctional complexes (Yamagata et al., 1995; Fannon and Colman, 1996; Uchida et al., 1996). Confocal microscopic data indicate that $\mathrm{N}$-cadherin codistributes with both pre- and postsynaptic elements and often seems to be concentrated around presynaptic boutons like a cup or ring around a ball (Fannon and Colman, 1996) (Fig. 3). Biochemical data indicate that $\mathrm{N}$-cadherin is a major postsynaptic density protein (Beesley et al., 1995). The precise threedimensional localization of cadherins with respect to the zone of synaptic vesicle release remains to be determined conclusively, but based on the evidence available, it would seem that whether cadherins are evenly distributed across the entire active zone, intercalated as spot welds, or surrounding the active zone, they could effectively adhere to and stabilize pre- and postsynaptic membranes (e.g., Spacek and Harris, 1998).

Adhesion between differentially localized cadherins may underlie some of the characteristic morphological differences observed between synapses of which asymmetric and symmetric synaptic junctions are among the best characterized examples (Gray, 1959; Peters et al., 1991; Peters and Palay, 1996). At asymmetric synapses, the distance between pre- and postsynaptic membranes is $\sim 30 \mathrm{~nm}$ (Peters and Palay, 1996), a distance that matches the predicted membrane separation for N-cadherinbased adhesive junctions (Shapiro et al., 1995). At symmetric synapses, the separation is somewhat smaller $(\sim 20 \mathrm{~nm})$ (Peters and Palay, 1996) but remains well within the range observed at other cadherin-mediated junctions (Farquhar and Palade, 1963; Overton, 1971; McNutt and Weinstein, 1973; Staehelin, 1974). Cadherins are relatively similar to one another in size, but the structure and intermolecular interactions that have been predicted for $\mathrm{N}$ - and $\mathrm{E}$-cadherin are distinct from one another and can serve as a basis for predicting slightly different intermembrane distances at junctions mediated by different cadherins (Overduin et al., 1995; Shapiro et al., 1995; Nadar et al., 1996).

\section{$\mathrm{N}$-cadherin and $\boldsymbol{\beta}$-catenin cluster at early synaptic sites}

For cadherins to bind homophilically across synapses, they must be placed in opposing membrane surfaces in both pre- and postsynaptic compartments. Consistent with this function, we find $\mathrm{N}$-cadherin and $\beta$-catenin distributed diffusely in both preand postsynaptic compartments before synapse formation. Approximately coincident with synaptic vesicle accumulation, both proteins become clustered at synaptic sites, and the diffuse dis- tribution, particularly of N-cadherin, is lost (compare Figs. 2, 3). This progressive change in localization is remarkably similar to the events leading to the assembly of desmosomes-specialized cadherin junctions. Before desmosome formation, junctional components are found in cytoplasmic pools of punctate labeling (Pasdar and Nelson, 1988). After cell-cell contact and in the absence of new protein synthesis, desmosomes form and cytoplasmic puncta disappear, suggesting that the cytoplasmic puncta were a recruitable pool of junctional components (Hennings and Holbrook, 1983; Pasdar and Nelson, 1988). The similarity between these two sets of data strongly suggests that before synapse formation, $\mathrm{N}$-cadherin and $\beta$-catenin exist as recruitable pools of molecules that, after contact, can be rapidly assembled into synaptic junctions and may therefore be involved in some of the initial adhesion events underlying formation of synaptic junctions (see also Colman, 1997). However, the present data also indicate that $\mathrm{N}$-cadherin and $\beta$-catenin are not concentrated particularly within and are often absent from axonal growth cones and their filopodia, which are thought to initiate synaptogenic interactions (Vaughn, 1989; Cooper and Smith, 1992). Integrins, immunoglobulin superfamily members, and the potentially adhesive neuroligins/ $\beta$-neurexins or densin 180-type proteins remain better candidates for initiating contact (Apperson et al., 1996; Einheber et al., 1996; Irie et al., 1997; Schachner, 1997). A more likely role for cadherins would be to stabilize appropriate pathfinding decisions. This interpretation correlates well with the detection and accumulation of $\mathrm{N}$-cadherin at the onset of synaptogenesis (but not before) in the developing chick optic tectum (Yamagata et al., 1995).

\section{$\mathbf{N}$-cadherin is lost from inhibitory synaptic sites}

What might account for the shift in cadherin localization observed at inhibitory synapses between 7 and $14 \mathrm{~d}$ in culture? It is possible that all inhibitory synapses containing $\mathrm{N}$-cadherin are eliminated selectively, but the number of GABAergic synapses increases linearly over the same time period (Bähr and Wolff, 1985; Benson and Cohen, 1996), making this unlikely. Given that at intermediate time points faint $\mathrm{N}$-cadherin label was detected at some inhibitory synapse sites, it seems more likely that $\mathrm{N}$-cadherin may be downregulated at maturing inhibitory synapses and that new inhibitory synaptic complexes in mature cultures incorporate an alternate cadherin. It remains possible that $\beta$-catenin clusters at inhibitory synapses by a cadherinindependent mechanism (e.g., Senda et al., 1998), but there have been reported as many as 38 cadherin and cadherin-related molecules in brain (Ranscht and Dours-Zimmerman, 1991; Suzuki et al., 1991; Sano et al., 1993; Sugimoto et al., 1996; Shibata et al., 1997), and we predict that one or several correspond to an "inhibitory synapse cadherin."

The shift in N-cadherin localization may simply reflect the maturation of an appropriate targeting mechanism. Although little is known of the cellular machinery required, a number of studies have demonstrated that neurotransmitter receptors are differentially distributed within dendrites (Gazzaley et al., 1997; Rubio and Wenthold, 1997) and are usually clustered only opposite their corresponding synaptic terminal (Craig et al., 1994; Baude et al., 1995; Roche and Huganir, 1995). Interestingly, the restriction of $\mathrm{N}$-cadherin to excitatory synapses is coincident with the time at which AMPA and GABA-A receptors first cluster beneath their neurotransmitter-containing terminals (Craig et al., 1994; Verderio et al., 1994). 


\section{Dual role for $\boldsymbol{\beta}$-catenin in neurons}

The present data show that $\beta$-catenin clusters associate with synaptophysin-labeled boutons at all stages of synaptogenesis. This strongly suggests that cadherins are components of all synaptic junctions in hippocampal cultures and that cadherin interactions at synapses closely resemble cadherin-mediated adhesion at adherens junctions.

Independent of its role in adhesion, $\beta$-catenin is also a signal transduction molecule in the Wnt/wingless growth factor pathway that mediates dorsal-ventral and anterior-posterior axes formation in developing vertebrates and anterior-posterior patterning in developing Drosophila (via armadillo, a $\beta$-catenin homolog) (Heasman et al., 1994; Peifer, 1995; Sanson et al., 1996; Fagotto et al., 1997). Wnt signaling appears to be transduced through a stabilized pool of cytoplasmic $\beta$-catenin that via its interaction with LEF/TCF DNA binding proteins can enter the nucleus and regulate transcription (Funayama et al., 1995; Gumbiner, 1995; Huber et al., 1996; Miller and Moon, 1997). In differentiated cells, cytoplasmic $\beta$-catenin seems to be tightly controlled in that rising levels and the resulting activation of Wnt pathway elements can lead to malignant transformation of some cells (Rubinfeld et al., 1997). Taken in this context, we found it surprising that $\beta$-catenin was readily detected within the nuclei of neurons that have terminally differentiated. These data suggest that in addition to events leading to cell division, Wnt-like signaling pathways may also be invoked during cell differentiation (see also Pollack et al., 1997).

\section{Adhesion and synapses}

Recent data strongly link changes in adhesion with alterations in the functional properties of synapses (Lüthi et al., 1994; Rønn et al., 1995; Muller et al., 1996; Bahr et al., 1977; Grotwiel et al., 1998; Staubli et al., 1998). In particular, Schuman and colleagues have demonstrated that disruptions of cadherin-based adhesion attenuated induction of long-term potentiation (Tang et al., 1998). Given our findings that suggest cadherins systematically differentiate between functionally distinct synaptic sites, cadherins together with catenins may be able to regulate aspects of synaptic junction adhesion and perhaps even synaptically driven changes in neuron morphology (e.g., Desmond and Levy, 1986; Geinisman et al., 1994).

\section{REFERENCES}

Amagai M, Karpati S, Prussick R, Klaus-Kovtun V, Stanley JR (1992) Autoantibodies against the amino-terminal cadherin-like binding domain of pemphigus vulgaris antigen are pathogenic. J Clin Invest 90:919-926.

Apperson ML, Moon IS, Kennedy MB (1996) Characterization of densin-180, a new brain-specific synaptic protein of the O-sialoglycoprotein family. J Neurosci 16:6839-6852.

Arndt K, Redies C (1996) Restricted expression of R-cadherin by brain nuclei and neural circuits of the developing chicken brain. J Comp Neurol 373:373-399.

Arndt K, Nakagawa S, Takeichi M, Redies C (1998) Cadherin-defined segments and parasagittal cell ribbons in the developing chicken cerebellum. Mol Cell Neurosci 10:211-228.

Bahr BA, Staubli U, Xiao P, Chun D, Ji Z-X, Esteban ET, Lynch G (1997) Arg-Gly-Asp-Ser-selective adhesion and the stabilization of long-term potentiation: pharmacological studies and the characterization of a candidate matrix receptor. J Neurosci 17:1320-1329.

Bähr S, Wolff JR (1985) Postnatal development of axosomatic synapses in the rat visual cortex: morphogenesis and quantitative evaluation. J Comp Neurol 233:405-420.

Baude A, Nusser Z, Molnár E, McIlhinney RAJ, Somogyi P (1995) High-resolution immunogold localization of AMPA type glutamate receptor subunits at synaptic and non-synaptic sites in rat hippocampus. Neuroscience 69:1031-1055.

Beesley PW, Mummery R, Tibaldi J (1995) N-cadherin is a major glycoprotein component of isolated rat forebrain postsynaptic densities. J Neurochem 64:2288-2294.

Benson DL, Cohen PA (1996) Activity-independent segregation of excitatory and inhibitory synaptic terminals in cultured hippocampal neurons. J Neurosci 16:6424-6432.

Benson DL, Isackson PJ, Gall CM, Jones EG (1992) Contrasting patterns in the localization of glutamic acid decarboxylase and $\mathrm{Ca}^{2+} /$ calmodulin protein kinase gene expression in the rat central nervous system. Neuroscience 46:825-849.

Benson DL, Watkins FH, Steward O, Banker G (1994) Characterization of GABAergic neurons in hippocampal cell cultures. J Neurocytol 23:279-295.

Binder LI, Frankfurter A, Rebhun LI (1986) Differential localization of MAP2 and tau in mammalian neurons in situ. Ann NY Acad Sci 466:145-167.

Bottenstein JE, Sato GE (1979) Growth of a rat neuroblastoma cell line in serum-free supplemented medium. Proc Natl Acad Sci USA 76:514-519.

Chang Y-C, Gottlieb DI (1988) Characterization of the proteins purified with monoclonal antibodies to glutamic acid decarboxylase. J Neurosci 8:2123-2130.

Colman DR (1997) Neurites, synapses, and cadherins reconciled. Mol Cell Neurosci 10:1-6.

Cooper MW, Smith SJ (1992) A real-time analysis of growth cone-target cell interactions during the formation of stable contacts between hippocampal neurons in culture. J Neurobiol 23:814-828.

Cox RT, Kirkpatrick C, Peifer M (1996) Armadillo is required for adherens junction assembly, cell polarity and morphogenesis during Drosophila embryogenesis. J Cell Biol 134:133-148.

Craig AM, Blackstone CD, Huganir RL, Banker G (1994) Selective clustering of glutamate and $\gamma$-aminobutyric acid receptors opposite terminals releasing the corresponding neurotransmitters. Proc Natl Acad Sci USA 91:12373-12377.

Desmond NL, Levy WB (1986) Changes in the postsynaptic density with long-term potentiation in the dentate gyrus. J Comp Neurol 253:476-482.

Einheber S, Schnapp LM, Salzer JL, Cappiello ZB, Milner TA (1996) Regional and ultrastructural distribution of the alpha 8 integrin subunit in developing and adult rat brain suggests a role in synaptic function. J Comp Neurol 370:105-134.

Fagotto F, Guger K, Gumbiner BM (1997) Induction of the primary dorsalizing center in Xenopus by the Wnt/GSK/ $\beta$-catenin signaling pathway, but not by Vg1, activin or noggin. Development 124:453-460.

Fannon AM, Colman DR (1996) A model for central synaptic junctional complex formation based on the differential adhesive specificities of the cadherins. Neuron 17:423-434.

Farquhar MG, Palade GE (1963) Junctional complexes in various epithelia. J Cell Biol 17:375-412.

Fletcher TL, Cameron P, De Camilli P, Banker G (1991) The distribution of synapsin I and synaptophysin in hippocampal neurons developing in culture. J Neurosci 11:1617-1626.

Fletcher TL, De Camilli P, Banker G (1994) Synaptogenesis in hippocampal cultures: evidence indicating that axons and dendrites become competent to form synapses at different stages of neuronal development. J Neurosci 14:6695-6706.

Funayama N, Fagotto F, McCrea P, Gumbiner BM (1995) Embryonic axis induction by the armadillo repeat domain of $\beta$-catenin: evidence for intracellular signaling. J Cell Biol 128:959-968.

Gazzaley AH, Benson DL, Huntley GW, Morrison JH (1997) Differential subcellular regulation of NMDAR1 protein and mRNA in dendrites of dentate gyrus granule cells after perforant path transection. J Neurosci 17:2006-2017.

Geiger B, Ayalon O (1992) Cadherins. Annu Rev Cell Biol 8:307-332. Geinisman Y, De Toledo-Morrell L, Morrell F (1994) Comparison of structural synaptic modifications induced by long-term potentiation in the hippocampal dentate gyrus of young adult and aged rats. Ann NY Acad Sci 747:452-466.

Goslin K, Banker G (1991) Rat hippocampal neurons in low density culture. In: Culturing nerve cells (Banker G, Goslin K, eds), pp 251282. Cambridge, MA: MIT. 
Gray EG (1959) Axo-somatic and axo-dendritic synapses of the cerebral cortex: an electron microscope study. J Anat 93:420-433.

Grotewiel MS, Beck CDO, Hang Wu K, Zhu X-R, Davis RL (1998) Integrin-mediated short-term memory in Drosophila. Nature 391:455-460.

Grunwald GB (1996) Discovery and analysis of the classical cadherins. Adv Mol Cell Biol 16:63-112.

Gumbiner BM (1995) Signal transduction by $\beta$-catenin. Curr Opin Cell Biol 7:634-640.

Gumbiner BM (1997) Carcinogenesis: a balance between $\beta$-catenin and APC. Curr Biol 7:R443-R446.

Gumbiner BM, McCrea PD (1993) Catenins as mediators of the cytoplasmic functions of cadherins. J Cell Sci [Suppl] 17:155-158.

Haegel H, Larue L, Ohsugi M, Fedorov L, Herrenknecht K, Kemler R (1995) Lack of $\beta$-catenin affects mouse development at gastrulation. Development 121:3529-3537.

Hatta K, Takeichi M (1986) Expression of N-cadherin adhesion molecules associated with early morphogenetic events in chick development. Nature 320:447-449.

Heasman J, Crawford A, Goldstone K, Garner-Hamrick P, Gumbiner B, McCrea P, Kintner C, Yoshida Noro C, Wylie C (1994) Overexpression of cadherins and underexpression of $\beta$-catenin inhibit dorsal mesoderm induction in early Xenopus embryos. Cell 79:791-803.

Hennings H, Holbrook KA (1983) Calcium regulation of cell-cell contact and differentiation of epidermal cells in culture. Exp Cell Res 143:127-142.

Huber O, Korn R, McLaughlin J, Ohsugi M, Herrmann BG, Kemler R (1996) Nuclear localization of beta-catenin by interaction with transcription factor LEF-1. Mech Dev 59:3-10.

Hunt CA, Schenker LJ, Kennedy MB (1996) PSD-95 is associated with the postsynaptic density and not with the presynaptic membrane at forebrain synapses. J Neurosci 16:1380-1388.

Inoue A, Sanes JR (1997) Lamina-specific connectivity in the brain: regulation by $\mathrm{N}$-cadherin, neurotrophins, and glycoconjugates. Science 276:1428-1431.

Irie M, Hata Y, Takeuchi M, Ichtchenko K, Toyoda A, Hirao K, Takai Y, Rosahl TW, Sudhof TC (1997) Binding of neuroligins to PSD-95. Science 277:1511-1515.

Kemler R (1993) From cadherins to catenins: cytoplasmic protein interactions and regulation of cell adhesion. Trends Genet 9:317-321.

Knudsen KA, Peralta Soler A, Johnson KR, Wheelock MJ (1995) Interaction of $\alpha$-actinin with the cadherin/catenin cell-cell adhesion complex via $\alpha$-catenin. J Cell Biol 130:67-77.

Lüthi A, Parent J-P, Figurov D, Muller D, Schachner M (1994) Hippocampal long-term potentiation and neural cell adhesion molecules L1 and NCAM. Nature 372:777-779.

McNutt NS, Weinstein RS (1973) Membrane ultrastructure at mammalian intercellular junctions. Prog Biophys Mol Biol 26:45-101.

Miller JR, Moon RT (1997) Analysis of the signaling activities of localization mutants of $\beta$-catenin during axis specification in Xenopus. J Cell Biol 139:229-243

Muller D, Wang C, Skibo G, Toni N, Cremer H, Calaora V, Rougon G, Kiss JZ (1996) PSA-NCAM is required for activity-induced synaptic plasticity. Neuron 17:413-422.

Nadar B, Overduin M, Ikura M, Rini JM (1996) Structural basis of calcium-induced E-cadherin rigidification and dimerization. Nature 380:360-364

Nagafuchi A, Takeichi M (1988) Cell binding function of E-cadherin is regulated by the cytoplasmic domain. EMBO J 7:3679-3684.

Nagafuchi A, Takeichi M (1989) Transmembrane control of cadherinmediated cell adhesion: a $94 \mathrm{kDa}$ protein functionally associated with a specific region of the cytoplasmic domain of E-cadherin. Cell Regul 1:37-44.

Nakagawa S, Takeichi M (1995) Neural crest cell-cell adhesion controlled by sequential and subpopulation-specific expression of novel cadherins. Development 121:1321-1332.

Navone F, Di Gioia G, Jahn R, Browning M, Greengard P, De Camilli P (1989) Microvesicles of the neurohypophysis are biochemically related to small synaptic vesicles of presynaptic nerve terminals. J Cell Biol 109:3425-3433

Nose A, Tsuji K, Takeichi M (1990) Location of specificity determining sites in cadherin cell adhesion molecules. Cell 61:147-155.
Overduin M, Harvey TS, Bagby S, Tong KI, Yau P, Takeichi M, Ikura M (1995) Solution structure of the epithelial cadherin domain responsible for selective cell adhesion. Science 267:386-389.

Overton J (1971) Fine structure of the developing gastric epithelium of the chick. J Morphol 133:375-386.

Oyama T, Kanai Y, Ochiai A, Akimoto S, Oda T, Yanagihara K, Nagafuchi A, Tsukita S, Shibamoto S, Ito F (1994) A truncated $\beta$-catenin disrupts the interaction between E-cadherin and $\alpha$-catenin: a cause of loss of intercellular adhesiveness in human cancer cell lines. Cancer Res 54:6282-6287.

Ozawa M, Ringwald M, Kemler R (1990) Uvomorulin-catenin complex formation is regulated by a specific domain in the cytoplasmic region of the cell adhesion molecule. Proc Natl Acad Sci USA 87:4246-4250.

Pasdar M, Nelson WJ (1988) Kinetics of desmosome assembly in MadinDarby canine kidney epithelial cells: temporal and spatial regulation of desmoplakin organization and stabilization upon cell-cell contact. II. Morphological analysis. J Cell Biol 196:687-695.

Peifer M (1995) Cell adhesion and signal transduction: the Armadillo connection. Trends Cell Biol 5:224-229.

Peifer M, Orsulic S, Sweeton D, Wieschaus E (1993) A role for the Drosophila segment polarity gene armadillo in cell adhesion and cytoskeletal integrity during oogenesis. Development 118:1191-1207.

Peters A, Palay SL (1996) The morphology of synapses. J Neurocytol 25:687-700

Peters A, Palay SL, Webster HD (1991) The fine structure of the nervous system. New York: Oxford UP.

Pollack AL, Barth AIM, Altschuler Y, Nelson WJ, Mostov KE (1997) Dynamics of $\beta$-catenin interactions with APC protein regulate epithelial tubulogenesis. J Cell Biol 137:1651-1662.

Ranscht B, Dours-Zimmerman MT (1991) T-cadherin, a novel cadherin cell adhesion molecule in the nervous system lacks the conserved cytoplasmic region. Neuron 7:391-402.

Redies C, Inuzuka H, Takeichi M (1992) Restricted expression of N- and R-cadherin on neurites of the developing chicken CNS. J Neurosci $12: 3525-3534$.

Ribak CE (1978) Aspinous and sparsely spinous stellate neurons in the visual cortex of rats contain glutamic acid decarboxylase. J Neurocytol 7:461-478.

Rimm DL, Koslov ER, Kebriaei P, Cianci CD, Morrow JS (1995) Alpha1 (E)-catenin is an actin-binding and -bundling protein mediating the attachment of F-actin to the membrane adhesion complex. Proc Natl Acad Sci USA 92:8813-8817.

Roche KW, Huganir RL (1995) Synaptic expression of the high-affinity kainate receptor subunit KA2 in hippocampal cultures. Neuroscience 69:383-393.

Rønn LCB, Bock E, Linnemann D, Jahnsen HJ (1995) NCAMantibodies modulate induction of long-term potentiation in rat hippocampal CA1. Brain Res 677:145-151.

Rubinfeld B, Robbins P, El-Gamil M, Albert I, Porfiri E, Polakis P (1997) Stabilization of $\beta$-catenin by genetic defects in melanoma cell lines. Science 275:1790-1792

Rubio ME, Wenthold RJ (1997) Glutamate receptors are selectively targeted to postsynaptic sites in neurons. Neuron 18:939-950.

Sano K, Tanihara H, Heimark RL, Obata S, Davidson M, St John T, Taketani S, Suzuki S (1993) Protocadherins: a large family of cadherin-related molecules in central nervous system. EMBO J 12:2249-2256.

Sanson B, White P, Vincent J-P (1996) Uncoupling cadherin-based adhesion from wingless signaling in Drosophila. Nature 383:627-630.

Schachner M (1997) Neural recognition molecules and synaptic plasticity. Curr Opin Cell Biol 9:627-634.

Senda T, Iino S, Matsushita K, Matsumine A, Kobayashi S, Akiyama T (1998) Localization of the adenomatous polyposis coli tumour suppressor protein in the mouse central nervous system. Neuroscience 83:857-866.

Serafini T (1997) An old friend in a new home: cadherins at the synapse Trends Neurosci 20:322-323.

Shapiro L (1997) The multi-talented $\beta$-catenin makes its first appearance. Structure 5:1265-1268.

Shapiro L, Fannon AM, Kwong PD, Thompson A, Lehman MS, Grübel G, Legrand J, Als-Nielsen J, Colman DR, Hendrickson WA (1995) Structural basis of cell-cell adhesion by cadherins. Nature 374:327-337. 
Shibata T, Shimoyama Y, Gotoh M, Hirohashi S (1997) Identification of human cadherin-14, a novel neurally specific type II cadherin, by protein interaction cloning. J Biol Chem 272:5236-5240.

Spacek J, Harris KM (1998) Three-dimensional organization of cell adhesion junctions at synapses and dendritic spines in area CA1 of the rat hippocampus. J Comp Neurol 393:58-68.

Staehelin LA (1974) Structure and function of intercellular junctions. Int Rev Cytol 39:191-283.

Staubli U, Chun D, Lynch G (1998) Time-dependent reversal of longterm potentiation by an integrin antagonist. J Neurosci 18:3460-3469.

Sugimoto K, Honda S, Yamamoto T, Ueki T, Monden M, Kaji A, Matsumoto K, Nakamura T (1996) Molecular cloning and characterization of a newly identified member of the cadherin family, PBcadherin. J Biol Chem 271:11548-11556.

Suzuki S, Sano K, Tanihara H (1991) Diversity of the cadherin family: evidence for eight new cadherins in nervous tissue. Cell Regul $2: 261-270$.

Suzuki SC, Inoue T, Kimura Y, Tanka T, Takeichi M (1997) Neuronal circuits are subdivided by differential expression of type II classic cadherins in postnatal mouse brains. Mol Cell Neurosci 9:433-447.
Takeichi M (1991) Cadherin cell adhesion receptors as a morphogenetic regulator. Science 25:1451-1455.

Tang L, Hung CP, Schuman EM (1998) A role for the cadherin family of cell adhesion molecules in hippocampal long-term potentiation. Neuron 20 , in press.

Uchida N, Honjo Y, Johnson KR, Wheelock MJ, Takeichi M (1996) The catenin/cadherin adhesion system is localized in synaptic junctions bordering transmitter release zones. J Cell Biol 135:767-779.

Vaughn JE (1989) Review: fine structure of synaptogenesis in the vertebrate central nervous system. Synapse 3:255-285.

Verderio C, Silvia C, Fumagalli G, Matteoli M (1994) Spatial changes in calcium signaling during the establishment of neuronal polarity and synaptogenesis. J Cell Biol 126:1527-1536.

Wöhrn J-CP, Puelles L, Nakagawa S, Takeichi M, Redies C (1998) Cadherin expression in the retina and retinofugal pathways of the chicken embryo. J Comp Neurol 396:20-38.

Yamagata M, Herman JP, Sanes JR (1995) Lamina-specific expression of adhesion molecules in developing chick optic tectum. J Neurosci 15:4556-4571. 